\title{
ХРОНИЧЕСКАЯ АЛКОГОЛЬНАЯ ИНТОКСИКАЦИЯ И КОМОРБИДНЫЕ РАССТРОЙСТВА КИШЕЧНИКА (ОБЗОР ЛИТЕРАТУРЫ)
}

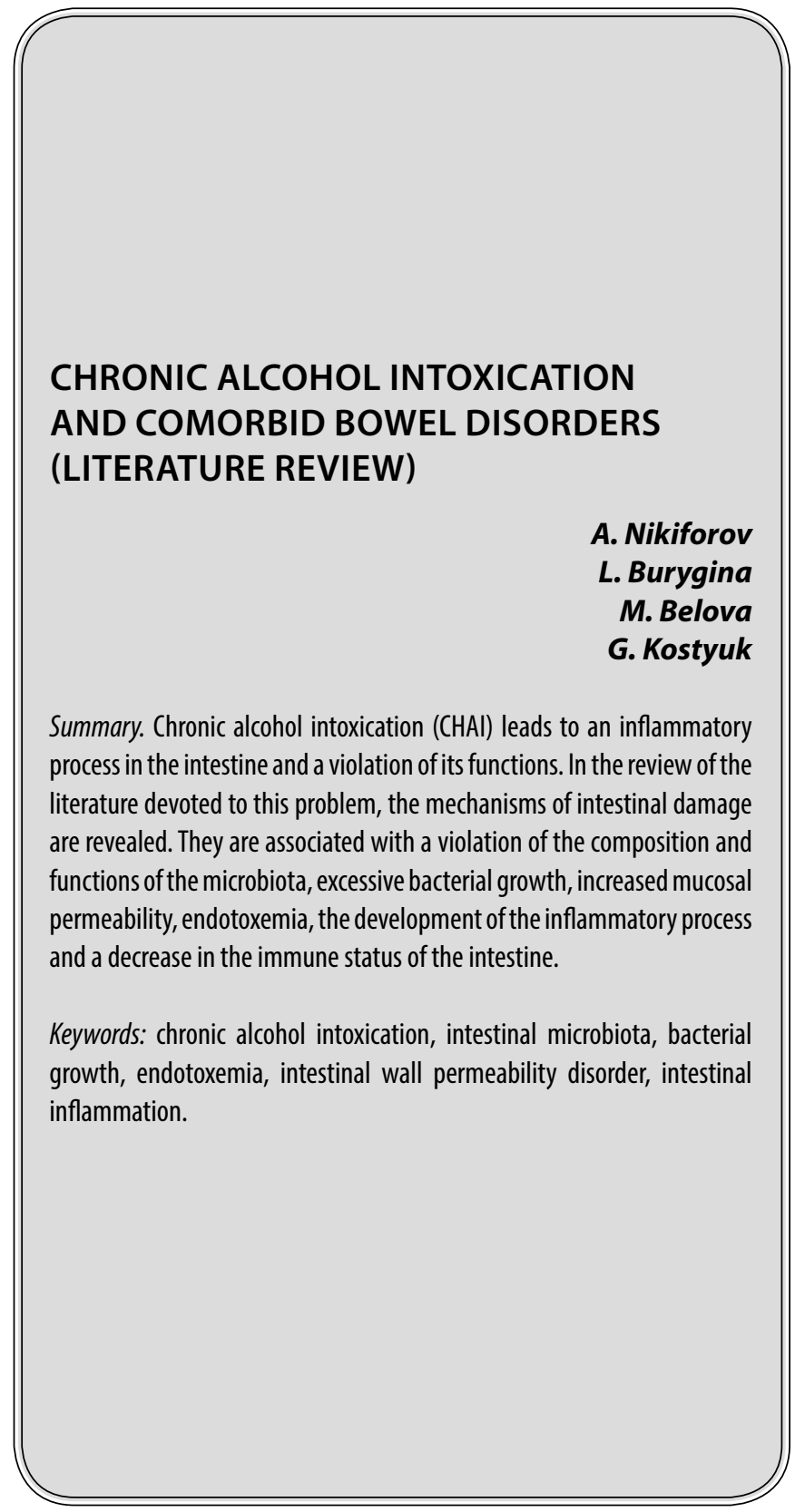

$\mathbf{X}$ АИ является одной из самых актуальных медико-социальных проблем общества. Это определяющий фактор возникновения основных причин смертности и ранней инвалидизации лиц молодого и трудоспособного возраста. Высокий уровень распространенности соматической патологии, связанной с ХАИ, находится в прямой зависимости от уровня потребления алкоголя в популяции.
Никифоров Игорь Анатольевич

Д.м.н., профессор, Академия постдипломного образования «Федеральный научно-клинический чентр специализированных видов медицинской помощи и медицинских технологий Федерального медико-

биологического агентства» narkolog.ipk@mail.ru

Бурыгина Лариса Андреевна

Главный врач, Психиатрическая клиническая больница № 4 им. П.Б. Ганнушкина Департамента здравоохранения города Москвы

Белова Майя Юрьевна

Заместитель главного врача, Психиатрическая клиническая больнича № 4 им. П.Б. Ганнушкина Департамента здравоохранения города Москвы; Психиатрический стационар им. В.А. Гиляровского

Костюк Георгий Петрович

Д.м.н., профессор, Главный врач, Психиатрическая клиническая больнича № 1 им. Н.А. Алексеева Департамента здравоохранения города Москвы

Аннотация. Хроническая алкогольная интоксикация (ХАИ) приводит к воспалительному процессу в кишечнике и нарушению его функций. В обзоре литературы, посвящённом этой проблеме, вскрыты механизмы поражения кишечника. Они связаны с нарушением состава и функций микробиоты, избыточным бактериальным ростом, увеличением проницаемости слизистой оболочки, эндотоксемией, развитием воспалительного процесса и уменьшением иммунного статуса кишечника.

Ключевые слова: хроническая алкогольная интоксикация, микробиота кишечника, бактериальный рост, эндотоксемия, нарушение проницаемости кишечной стенки, воспаление кишечника.

По данным Росстата потребление алкоголя в России составляет 9,3 л. в год, число больных алкоголизмом оценивается в 1,3 млн. человек (interfax.ru 60 80601).

В год от отравления алкоголем умирает 6 тыс. человек (mk.ru 2020/05/26 narkolog - rossii). Смертность от причин, связанных с употреблением алкоголя, оценивается как $17,4 \%$, а отдельными авторами и $23,4 \%$. 
В последние годы многими исследователями разрабатывается тема коморбидных ХАИ заболеваний, к которым относятся патологические состояния, вызванные токсическим действием алкоголя и его метаболитов и характеризующимися тяжелыми медицинскими последствиями для организма в целом [1, 2].

Злоупотребление этанолом приводит к полиорганной недостаточности, алкогольной висцеропатии комплексу соматических заболеваний, причиной которых является токсическое влияние алкоголя в условиях ХАИ. Способность алкоголя вызывать токсические изменения практически во всех органах и системах обусловлено его химическими свойствами и особенностями его биотрансформации $[3,4]$.

Частота алкогольной висцеропатии у пациентов, госпитализированных по поводу декомпенсации соматической патологии, составляет около $32 \%$ [5].

Большой интерес вызывает проблема влияния алкоголя на кишечник, поскольку органы ЖКТ выполняют барьерную функцию на пути проникновения алкоголя в организм и первыми испытывают его негативное воздействие.

Алкоголь всасывается в верхних отделах кишечника путем диффузии. Концентрация алкоголя в просвете дистальных отделов тонкой кишки через час после употребления алкоголя составляет 200 мг/100 мл после употребления 2-х «стандартных доз» алкоголя (100 мл крепких напитков 40\%).

Значительная часть метаболизма алкоголя происходит в печени путем окислительного преобразования в процессе которого алкогольдегидрогеназа (АДГ) превращает алкоголь в токсический продукт-ацетальдегид. Затем альдегиддегидрогеназа (АлДГ) превращает ацетальдегид в ацетат.

Второй путь метаболизма алкоголя осуществляется через микросомальную этанол-окислительную систему (МЭОС). В процессе образуется много свободных радикалов, которые вызывают повреждения клеток [6].

Третий путь - неокислительный метаболизм этанола через реакции с фосфолипидами или свободными жирными кислотами мембран [7].

Ещё один путь накопление ацетальдегида в кишечнике - синтез его разными представителями микробиоты.

ХАИ приводит к нарушению гомеостаза тканей и развитию хронических воспалительных процессов в кишечнике [8]. Это происходит и за счёт изменения состава микробиоты [9], нарушения функции кишечника [10], увеличения проницаемости слизистой оболочки кишечника [11] и нарушения иммунной системы этого органа.

\section{Аисбиоз кишечника}

В кишечнике обитают более 520 видов бактерий, как нейтральных так и патогенных, которые находятся в сбалансированном состоянии бактериального гомеостаза. При нарушении этого баланса возникает состояние «дисбиоза» $[12,13,14,15]$ что приводит к увеличению выброса эндотоксинов. На это реагируют иммунные клетки и белки, которые активируют процесс воспаления $[7,16,17]$.

ХАИ увеличивает количество кишечных бактерий [18, $19,20]$, что связано с нарушением функции пищеварения в кишечнике и аномальной перистальтикой, а также изменением метаболизма желчных кислот [21] снижением их уровня, снижением кислотности в желудке и изменением иммунного статуса [19]. Внутри микробиоты под действием ХАИ уменьшается количество полезных бактерий и увеличивается объем токсичных $[14,15,22]$.

Вследствие ХАИ доля бактероидов в толстом кишечнике уменьшается, а число протеобактерий увеличивается, за счёт грамотрицательных и актинобактерий [22, 23].

Избыточный бактериальный рост увеличивает риск воспаления т.к. бактерии сами вырабатывают ацетальдегид в толстой кишке, что увеличивает пул провоспалительных метаболитов алкоголя [24, 25].

Синдром избыточного бактериального роста приводит к повреждению слизистой оболочки тонкого кишечника и нарушению всасывания макронутриентов, таких как глюкоза, аминокислоты и липиды, витаминов В1, В6, В12, A, E, K, фолиевой кислоты, микроэлементов, что приводит к нарушению обмена веществ в организме и истощению пациентов $[19,26]$.

Прогрессирующие дисбиотические нарушения кишечной микробиоты в условиях ХАИ порождают сложную многокомпонентную систему по типу хронического токсико-инфекционного очага, связанного с нарушениями углеводного, белкового и липидного обменов, и изменением функций нервной и эндокринной систем, признаками системного воспаления [27].

\section{Изменение проницаемости кишечной стенки}

Повышенная проницаемость кишечника в условиях ХАИ, а здесь важнейшую роль играет ацетальдегид [28] 
и эндотоксины, создает условия для проникновения макромолекул (например, липополисахаридов) через кишечный барьер.

Нарушается как трансэпителиальная (через клетки эпителия) так и параклеточная (разрушая структуры цитоскелета и белковых связей между ворсинками) проницаемость $[29,30]$. Доказано и воздействие алкоголя на гены, определяющие целостность кишечного барьеpa [31].

Вследствие нарушения барьерной функции кишечника происходит миграция бактерий из просвета кишечника в мезентеральные и лимфатические узлы и портальный кровоток.

Решающую роль в нарушении барьерной функции кишечника играет ацетальдегид, как продукт метаболизма этанола, так и результат жизнедеятельности патогенных бактерий. Ацетальдегид воздействует на белки плотного и адгезивного контакта эпителия клеток кишечной стенки, вызывая их перераспределение и отделение от цитоскелета [19].

Диета богатая ненасыщенными жирами на фоне ХАИ увеличивает проницаемость кишечника, тогда как диета с насыщенными жирами - защищает его [32].

В условиях ХАИ происходит:

1. повреждение клеток аддуктами ДНК, образованные ацетальдегидом [33];

2. нарушение работы клеток свободными радикалами, возникающими в процессе метаболизма алкоголя путем окислительного стресса [34];

3. гибель клеток кишечника (изъязвление слизистой, эрозии, потеря эпителия на концах ворсинок) $[35,36]$.

\section{В^ияние на иммунную систему}

ХАИ оказывает влияние на иммунную систему кишечника:

- снижение иммунного ответа слизистой оболочки кишечника, что влечет повышенную восприимчивость к кишечным патогенам [37];

- повышение активности провоспалительных иммунных клеток, таких как лейкоциты и тучные клетки [19];

- повышение уровня эндотоксинов в кишечнике и как следствие активация локального, а затем и системного воспаления [38];

- ХАИ подавляет иммунный ответ кишечника, его слизистой оболочки, уменьшая количества секретируемых антимикробных молекул (клетки Панета) кишечных клеток, что, в свою очередь, приводит к чрезмерному бактериальному росту [21];

- ХАИ нарушает синтез сигнальных молекул и Т-клеток [39];

В условиях ХАИ развивается вторичный (приобретенный) иммунодефицит как следствие болезней, нарушений обмена веществ, истощения, авитаминоза, стрессов, травм. Развивается лимфоцитопения, моноцитопения и нейтрофилия. В результате подавления продукции провоспалительных цитокинов угнетаются клеточные и гуморальные иммунные процессы вследствие подавления функции Т-хелперов.

Вторичный иммунодефицит усугубляется нарушением процесса питания в условиях ХАИ и нарушения обмена веществ. Так, недостаток цинка снижает функцию Т-клеток, дефицит железа нарушает пролиферацию лимфоцитов и фагоцитарную способность нейтрофилов. Недостаток витамина А снижает численность ряда субпопуляций лимфоцитов, а дефицит витамина В6 и фолата нарушает клеточный иммунитет [32, 37, 40].

\section{ХАИ как Фактор онкогенеза}

ХАИ способствует развитию различных видов рака желудочно-кишечного тракта, включая колоректальный рак. Этому способствуют курение табака, метаболический синдром. Основными факторами риска являются алкоголь как прямой канцероген и воспаление кишечника [41].

Когда часть клеток кишечника малигнизируется, активность АДГ увеличивается, а активность АлДГ снижается [42]. Это приводит к увеличению скорости окисления и снижению способности элиминтировать метаболиты алкоголя, вызывая окислительный стресс и усугубляя воспалительный процесс в кишечнике.

\section{Механизмы \\ воспалительного прочесса}

Вызываемое ХАИ воспаление кишечника способствует повреждению печени за счет увеличения проницаемости и попадания в печень эндотоксинов $[43,44]$. В свою очередь, поражение печени приводит к активации воспалительных цитокинов, лейкотриенов и хемотоксинов, что ведет к хроническому воспалительному процессу в печени с перспективой развития фиброза $[45,46]$.

ХАИ вызывает индукцию других ферментных систем, метаболизирующих этанол, в частности Сур2Е1-изоформы макросомального цитохрома Р450. Активная работа этой системы приводит как к образованию ацетальдеги- 
да, так и к генерации больших количеств активных форм кислорода (АФК).

Комбинация ацетальдегида и супероксидного радикала, перекиси водорода, 1-гидроксиэтильного радикала (АФК) приводит к поражению не только кишечника, но и печени.

При избытке полиненасыщенных жирных кислот в диете (олеиновой, линолевой и др.) или высокого уровня жирных кислот в крови (ожирение, сахарный диабет II типа) повышается ДНК-связывающая активность пероксисомного пролифераторного альфа-рецептора (ППРа) в печени. Это индуцирует экспрессию генов микросомальных ферментов Сур4А1 и Сур4А2, что добавляет ацетальдегида и АФК. Активизируется 囚-окисление длинноцепочных жирных кислот, опосредованное Сур4А, с образованием токсичных дикарболовых кислот.

Сам этанол является субстратом для фермента каталазы, который образует токсичные продукты, что увеличивает пул кишечных эндотоксинов бактериального происхождения.

Отмечается важность синергичного действия этанола и цитокина ФНОа (раздельно их негативное влияние на клетки не приводит к их гибели) на митохондрии клеток, что снижает энергообеспеченность клеток и приводит и избыточному появлению АФК. Нарушается работа внутриклеточных защитных систем (антиоксидантной и антиапоптической), что приводит к гибели клеток [6, 43].

Локальные расстройства в зоне воспаления наряду с нарушением кровоснабжения и обменных процессов сочетаются с комплексом метаболических и функциональных расстройств на уровне целостного организма. Так, возбужденные в зоне воспаления нейтрофилы, моноциты, тканевые макрофаги продуцируют эндогенные пирогены (ИЛ-1, ИЛ-6, ФНОа), интерфероны, катионные белки, макрофагальный воспалительный белок. Эндогенные пирогены индуцируют развитие лихорадочной реакции. Межклеточные взаимодействия между мононуклеарными фагоцитами и иммунокомпетентными клетками осуществляется в зоне воспаления через высвобождение дитоксинов, которые определяют формирование системной реакции острой фазы. Это ИЛ-1, ИЛ-6, ФНОа, интерфероны. Влияние ИЛ-1 на ЦНС повышает уровень соматотропного гормона, что приводит к увеличению содержания глюкозы в плазме крови, свободных жирных кислот, аминокислот.

В печени происходит синтез белков острой фазы: С-реактивный белок, гаптоглобин, церулоплазмин, плазминоген, трансферрин и другие.
В условиях воспалительного процесса повышается способность эритроцитов к агглютинации, снижается величина отрицательного заряда их мембраны. Это приводит к увеличению скорости оседания эритроцитов.

Образование в зоне альтерации бактериальных экзои эндотоксинов, продуктов жизнедеятельности микроорганизмов при слабо выраженной защитной реакции макроорганизма, недостаточности барьеров, отделяющих очаг воспаления от здоровых тканей, приводит к поступлению их в системный кровоток, развитию интоксикации и системной воспалительной реакции.

Основными признаками синдрома системной воспалительной реакции являются:

- гормональный дисбаланс;

- увеличение содержания в крови белков острой фазы;

- лейкоцитоз более 12000 в 1 мкл;

- тахикардия более 90 ударов в минуту;

- гипертермия более $38^{\circ} \mathrm{C}$ Цельсия или гипотермия меньше $36^{\circ} \mathrm{C}$;

- частота дыхания свыше 20 раз в минуту.

Патогенез синдрома системной воспалительной реакции складывается из расстройств биологического окисления и определяется гипоэргизмом клетки, как следствием тканевой гипоксии, развивающейся под действием эндотоксемии [40].

Кишечная проницаемость, ассоциированная с ХАИ, влияет на показатели работы центральной нервной системы, повышая вероятность развития депрессии и тревоги $[47,48]$ и вегетативным расстройствам [49]. Высокий уровень цитокинов разрушает гемато-энцефалический барьер и, проникая в мозг, может повреждать таламус, гиппокамп, миндалевидное тело, префронтальную кору, вызывая психические и поведенческие расстройства $[50,51]$.

Таким образом, различными методологическими путями ХАИ вызывает воспаление кишечника, что приводит к развитию патологии широкого спектра как внутри, так и за пределами кишечника и желудочно-кишечного тракта. Само воспаление является результатом окислительного метаболизма алкоголя и приводит к бактериальному росту, дисбактериозу и повышению проницаемости клеточной стенки.

Повышение уровня знаний в этом вопросе позволит сформулировать новые стратегии в лечении алкогольной болезни и ее коморбидных расстройств, включая возможно диетологическое и бактериологическое направления, формируя комплексный междисциплинарный подход. 


\section{ЛИТЕРАТУРА}

1. Никифоров И.А., Никифоров И.И., Меркин А.Г., Коморбидные расстройства желудочно-кишечного тракта при злоупотреблении алкоголем (обзор литературы) // Учебно-методическое пособие. М.: 2014. 17 с.

2. Никифоров И.А., Костюк Г.П., Савельев Д.В., Бурыгина Л.А., Белова М.Ю., Никифоров И.И., Феномен коморбидности в наркологии //0 состоянии совершенствования последипломного профессионального образования в системе ФМБА России. Материалы научно-практической конференции, посвященной 30-летию Академии постдипломного образования ФГБУ ФНКЦ ФМБА России. М. 2019. с. 124-126.

3. Никифоров И.А., Чернобровкина Т.В., Жовнерчук Е.В. и др. Поражение печени при алкоголизме (обзор литературы) // Профилактическая медицина. 2014. 17(3). 55-61.

4. Никифоров И.А., Никифоров И.И., Аронов П.В. Алкогольная болезнь и коморбидные церебральные расстройства (обзор литературы) //Профилактическая медицина. 2015. 18(3). 47-54.

5. Верткин А.Л., Комаровский А.Н., Скотников А.С. Алкоголь-ассоциированные состояния в многопрофильном стационаре // Лечащий врач. $2011.9 .1-11$.

6. Таганович А.Д., Патологическая биохимия /Таганович А.Д., Олецкий Э.Н., Котович И.Л./ Под общей редакцией Тагановича А.Д. 2015. М.: Издательство БИHOM, $488 \mathrm{C}$

7. Elamin E.E. Masclee A.A., Dekker J., Jonkers D.M. Ethanol metabolism and its effects on the intestinal epithelial barrier // Nutrition Reviews. 2013. 71(7). 483-499.

8. Patel S., Behara R., Swanson G.R. et.al. Alcohol and the intestine // Biomolecules. 2015. 5(4). 2573-2588.

9. Engen P.A., Green S.J., Voigt R.M., et.al. The gastrointestinal microbiome: Alcohol effects on the composition of intestinal microbiota //Alcohol Research: Current Reviews. 2015.37 (2). 223-236.

10. Couch R.D., Dailey A., Zaidi F., et.al. Alcohol induced alterations to the human fecal VOC metabolome // PLos One. 2015. 10(3): e 0119362.

11. Tang Y., Zhang L., Forsyth C.B., et.al. The role of miR-212 and iNOS in alcohol-induced intestinal barrier dysfunction and steatohepatitis // Alcoholism: Clinical and Experimental Research. 2015. 39(9). 1632-1641.

12. Belizario J., Napolitano M., Human microbiomes and their roles in dysbiosis, common diseases and novel therapeutic approaches // Frontiers in microbiology. 2015. 6. 1050.

13. Ардатская, М.Д. Дисбиоз (дисбактериоз) кишечника: современное состояние проблемы, комплексная диагностика и лечебная коррекция / М.Д. Ардатская, С.В. Бельмер, В.П. Добрица, С.М. Захаренко, Л.Б. Лазбеник, О.Н. Минушкин, Л.С. Орешко, С.И. Ситкин, Е.И. Ткаченко, А.Н. Суворов, А.И. Хавкин, Б.А. Шендеров //Экспериментальная и клиническая гастроэнтерология. 2015. № 5 (117). с. $13-50$.

14. Кнышова Л.П. Состояние микробиоты кишечника на фоне хронической алкогольной интоксикации (Экспериментальное исследование). Автореферат диссертации канд. мед. наук. Волгоград. 2018.

15. Бакулин И.Г. Алкоголь и измеения микрофлоры кишечника: современные представления / И.Г. Бакулин, Н.В. Шаликиани// Доктор. Ру. Гасторэнтерология. 2016. № 1(118). С. 38-42.

16. Fung T.C., Olson C.A., Hsiao E.Y. Interactions between the microbiota, immune and nervous systems in health and disease // Nat. Neurosci. 2017. 20. p. 145-155.

17. Сидельникова В.И., Эндогенная интоксикация и воспаление: последовательность реакций и информативность маркеров / В.И. Сидельникова, А.Е. Черницкий, М.И. Рецкий// Сельскохозяйственная биология. 2015. Том 50. № 2. с. 152-161.

18. Canesso M.C.C., Lacerda N.L., Ferreira C.M., et.al. Comparing the effects of acute alcohol consumption in germ-free and convencional mice: the role of the gut microbiota //BMC Microbiology. 2014. 14. 240.

19. Бакулин И.Г., Шаликиани Н.В., Алкоголь и изменения микрофлоры кишечника: современные представления//Гастроэнтерология. 2016.1(118).38-42.

20. Топчий Т.В. Синдром избыточного бактериального роста в клинческой практике /Т.Б. Топчий, 0. Ню Минушкин, Ю.С. Скибина, А.Е. Евсиков //Экспериментальная и клиническая Гастроэнтерология. 2017. № 3 (139). с. 71-78.

21. Schnabl B., Brenner D.A., Interactions between the intestinal microbiome and liver diseases // Gastroenterology. 2014. 146(6). 1513-1524.

22. Bull-Offerson L., Feng W., Kirpich I., et.al. Metagenomic analyses of alcohol induced pathogenic alterations in the intestinal microbiomeand the effect of lactobacillus rhamnosus GG treatment // PLos One. 2013. 8(1): e 53028/

23. Yan A.W., Fouts D.E., Brandt J., Starkel P., et.al. Enteric dysbiosis associated with a mouse model of alcoholic liver disease/ Gepatology/ 2011. Vol. 53. № 1. P. 96-105.

24. Zhong W., Zhou Z. Alterations of the gut microbiome and metabolome in alcoholic liver disease / World Journal of Gastrointestinal Pathophysiology. 2014. 5(4). 514-522.

25. Минушкин 0.Н., Подходы к лечению больных синдромом избыточного бактериального роста в тонкой кишке, развившимся в связи с патологией верхних отделов желудочно-кишечного тракта /0.Н. Минушкин, Л.В. Масловский, Т.Б. Топчий, Ю.С. Скибина, А.Е. Евсиков // Лечащий врач. 2017. № 2, с. 40.

26. Никифоров И.А., Костюк Г.П., Савельев Д.В., Бурыгина Л.А., Белова М.Ю., Никифоров И.И., Хроническая алкогольная интоксикация и коморбидные расстройства желудочно-кишечного тракта //0 состоянии совершенствования последипломного профессионального образования В системе ФМБА России. Материалы научно-практической конференции, посвященной 30-летию Академии постдипломного образования ФГБУ ФНКЦ ФМБА России. М. 2019. c. 121-124.

27. Яковлев А.Т. Поройский С.В., Кнышова Л.П., Морковин Е.И. Изменение микробиоты кишечника при хронической алкоголизации /Самарский научный вестник. 2017. Т. 6 № 3 (20). с. 64-67.

28. Chen Y/Yang F., Lu H., Wang B. et.al. Characterization of fecal microbial communities in patients with liver cirrhosis / Hepatology. 2011. Vol 52. № 2. p. 562-572.

29. Dunagan M., Chandhry K., Samak G., Rao R.K Acetaldehyde disrupts tight junctions in Caco-2 cele monolayers by a protein phosphatase 2A-dependent mechanism / American Journal of Physiology Gastrointestinal and Liver Physiology. 2012/ 303(12). G 1356- G 1364 
30. Wang Y., Tong J., Chang B et.al. Effects of alcohol on intestinal epithelial barrier permeability and expression of tight junction — associated proteins /Molecular Medicine Reports. 2014. 9(6). 2352-2356.

31. Lippail D., Bala S., Catalani D., et.al. Micro-RNA-ISS de ticien prerents alcohol-induced serum endotoxin increase and small bowel inflammation in mice /Alcoholism: Clinical and Experimental Research. 2014. 38(8). 2217-2224.

32. Chen P., Torralba M., Tan J. et.al. Supplementation of saturated long-chain fatty acids maintains intestinal eubiosis and reduced ethanol — induced liver injury in mice / Gastroenterology. 2015. 148(1). 203-214.

33. Malaguarnera G., Giordano M., Nunnari G. et.al. Gut microbiota in alcoholic liver disease: Pathogenetic role and therapeutic perspectives

34. Forsyth C.B., Voigt R., Keshavarzian A. Intestinal CYP 2 E1: A mediator of alcohol-induced gut leakiness. // Redox Biology. 2014. 3. 40-46.

35. Pijls K.E., Jonkers D.M., Elamin E.E. et. al. Intestinal epithelial barrier function in liver cirrhosis: An extensive review of the literature // Liver International. 2013. 33(10) 1457-1469.

36. Rocco A., Compare D., Angrisani D. et. al. Alcoholic disease: Liver and beyond. // World Journal of Gastroenterology. 2014. 20(40). 14652-14659.

37. Zhou C., Zhao J., Li J. et al. Acute ethanol administration inhibits Toll-like receptor 4 signaling pathway in intestinal epithelia//Alcohol. 2013. 47(3). $231-239$.

38. Leclercq S., Cani P.D., Neyrinck A.M., et al. Role of intestinal permeability and inflammation in the biological and behavioral control of alcohol — dependent subjects.// Brain, Behavior, and Immunity. 2012. 26 (6). 911-918.

39. Trevejo-Nunez G., Chen K., Dufour J.P. et. al. Ethanol impairs mucosal immunity against streptococcus pneumoniae infection by disrupting interleukin 17 gene expression. // Infection and Immunity. 2015. 83(5). 2082-2088.

40. Клиническая патофизиология: курс лекций /под редакцией В.А. Черешнева, П.Ф. Литвицкого, В.Н. Цыгана. 2-е изд. испр. и доп. Санкт-Петербург. Спецлит. 2015. 472 c.

41. Thrift A.P., Pandeya N, Smith K.J. et al. Lifetime alcohol consumption and risk of Barrentt's esophagus. // American Journal of Gastroenterology. 2011. 106(7). $1220-1230$.

42. Testino G. The burden of cancer attributable to alcohol consumption. // Medica (Buchar). 2011.6 (4). 313-320.

43. Bishehsari E., Magrio E., Swanson G. et. al. Alcohol and gut-derived inflammation // Alcohol Research. 2017. 38(2). 163-171.

44. Костюкевич 0.И. Роль кишечной микробиоты в развитии заболеваний печени и желчевыводящих путей / О.И. Костюкевич, Н.А. Былова, А.С. Симбирцева // «РМЖ». Гастроэнтерология. 2016. № 11. с. 713-720.

45. Seki E., Schnabl B. Role of innate immunity and the microbiota in liver fibrosis: Crosstalk between the liver and gut. // Journal of Physiology. 2012.590 (3). 447-458

46. Szabo G., Lippai D. Converging actions of alcohol on liver and brain immune signaling. //International Review of Neurobiology. 2014. 118. 859-380.

47. Leclercq S, Cani P.D., Neyrinck A.M. et al. Role of intestinal permeability and inflammation in the biological and behavioral control of alcohol — dependent subjects // Brain. Behavior and Immunity. 2012. 26(6). 911-918.

48. Bercik P., Denou E., Collins J. et al. The intestinal microbiota affect central levels of brain-derived neutropic, factor and behavior in mice. // Gastroenterology. 2011. 141(2). 599-609/

49. Retson T.A., Hoek J.B., Sterling R.C., Van Bockstaele E.J. Amigdalar neuronal plasticity and the interactions of alcohol, sex, and stress. // Brain structure and Function. 2015. 220(6). 3211-3232.

50. Gorky J., Schwaber J. The role of the gut-brain axis in alcohol use disorders // Progress in Neuropsychopharmacology and Biological Psychiatry. 2016. 65. 234-241.

51. Federico A., Cotticelli G., Festi D. et al. The effects of alcohol on gastrointestinal tract, liver and pancreas: evidence based suggestions for clinical management // European Review for Medical and Pharmacological Sciences. 2015. 19. 1922-1940.

() Никифоров Игорь Анатольевич ( narkolog.ipk@mail.ru ), Бурыгина Лариса Андреевна,

Белова Майя Юрьевна, Костюк Георгий Петрович.

Журнал «Современная наука: актуальные проблемы теории и практики» 